\title{
BOTÂNICA NO CERRADO: A AULA DE CAMPO E AS COLEÇÕES BOTÂNICAS DIDÁTICAS ASSOCIADAS AS TECNOLOGIAS Digitais DA INFORMAÇÃo E COMUNICAÇÃo COMO ESTRATÉGIAS DE ENSINO
}

\author{
BOTANY IN THE CERRADO: THE FIELD CLASS AND THE DIDACTIC \\ BOTANICAL COLLECTIONS ASSOCIATED WITH DIGITAL TECHNOLOGIES OF \\ INFORMATION AND COMMUNICATION AS TEACHING STRATEGIES
}

DOI: 10.23926/RPD.2526-2149.2020.v5.n2.p1139-1154.id746

\section{Robson Aparecido dos Santos \\ Mestre em Ensino de \\ Biologia (UNEMAT) \\ Professor da educação básica de Mato Grosso. \\ robson.bio2017@gmail.com}

\section{Rogério Benedito da Silva Añez}

Doutor em Botânica (INPA)

Professor Adjunto da

Universidade do Estado de Mato Grosso (UNEMAT)

Docente do Programa de

Pós-Graduação em Ensino de Biologia

(PROFBIO/UNEMAT)

anez@unemat.br
Resumo: O presente artigo teve por objetivo, avaliar as possibilidades didáticas das aulas de campo e das coleções botânicas didáticas associadas ao uso de algumas tecnologias digitais para o enriquecimento do ensino de botânica. Para tanto, foi apresentado aos estudantes de uma escola estadual de ensino médio do município de Tangará da Serra, Mato Grosso, o projeto "Botânica no Cerrado", que permitiu por meio da realização de aulas de campo e laboratório, aliado ao uso de um grupo de WhatsApp e uso do Qr code, a ressignificação do ensino de botânica. Os alunos participantes demonstraram maior interesse pelas plantas e curiosidade pelas técnicas de campo e laboratório com o uso de métodos alternativos de ensino. Além disso, os recursos digitais utilizados permitiram atingir as expectativas dos jovens inseridos na era da internet e demonstraram ser ótimas ferramentas para auxiliar no processo de aprendizagem botânica. A coleção botânica didática construída no projeto servirá como estímulo aos demais alunos e professores de outras escolas do estado e assim poder ajudar na discussão e aprendizagem sobre a importância das plantas e seu conhecimento.

Palavras-chave: Botânica. Tecnologia. Aprendizagem.

Abstract: This article aimed to evaluate the didactic possibilities of field classes and didactic botanical collections associated with the use of some digital technologies to enrich the botany teaching. For this purpose, it was presented to the students from a state high school in the municipality of Tangará da Serra, Mato Grosso, Brasil, the "Botany in the Cerrado" project, which provided them, through the realization of field and laboratory classes, combined with the use of a WhatsApp group and the use of the QR code, the reframing of teaching botany. The students who participated in this Project, showed greater interest in plants and, curiosity in field and laboratory techniques with the use of alternative teaching methods. Moreover, the digital resources used have made it possible to reach the expectations of young people inserted in the internet age and have proved to be great tools to assist in the botanical learning process. The didactic botanical collection built in the Project, will serve as a stimulus to other students and teachers from other schools in the state and, thus, it can help in the discussion and learning about the importance of plants and their knowledge.

Keywords: Botany. Tecnology. Learning. 


\section{INTRODUÇÃO}

O ser humano em seu processo de adaptação e coexistência com as demais espécies, buscou entender e conhecer aquelas as quais poderia fazer uso para facilitar sua sobrevivência e garantir sua perpetuação enquanto espécie (FITA; NETO, 2007). Nesse sentido, a existência humana, passados milhares de anos de evolução, deixou de ser limitada por recursos disponíveis na natureza, e com isso, a domesticação de espécies animais e vegetais, permitiu ir além do entendimento utilitarista dos seres vivos, passando agora a ser possível entender a natureza e a importância dos seres que dela fazem parte para a manutenção do equilíbrio ambiental (LIMA; OLIVEIRA, 2011).

Apesar dessa consciência social sobre a importância da preservação e manutenção do ambiente natural para a própria sobrevivência do ser humano, ainda notamos o pouco interesse ou curiosidade despertada por um grupo de organismos sem os quais a vida não existiria da forma como a conhecemos, o grupo das plantas (MELO et al. 2012). Esse grupo, como comumente é ensinado nas escolas da rede de educação básica do Brasil, é muitas vezes abordado sem despertar o interesse e curiosidade dos alunos. Diversas pesquisas sobre o ensino de botânica têm apontado para a necessidade de revisão da prática docente e maior valorização das plantas no currículo das disciplinas de ciências e biologia (ARRAIS et al., 2014, MELO et al, 2012, SALATINO; BUCKERIDGE, 2016).

Mas de que te serve saber Botânica? Essa pergunta que intitula o artigo de Salatino \& Buckeridge (2016), nos remete aos diversos usos que fazemos da flora em nosso cotidiano, de nossas necessidades alimentares básicas até a importância estética e medicinal de várias plantas. Dessa forma, o ensino, seja dentro da área de ciências ou em outra área do conhecimento, enfrenta diversos problemas, como por exemplo, a infraestrutura das escolas e a capacitação docente. No entanto, o papel e ação docente nesse cenário são cruciais, visto que, uma simples mudança de abordagem didática pode trazer muitos ganhos em qualidade e significância para a educação ofertada aos estudantes (ARRAIS et al., 2014).

Quanto aos estudantes, será que estes estão sendo estimulados a despertar a sua curiosidade pelo estudo das plantas? Essa é uma pergunta que vem atraído a atenção de diversos pesquisadores da área de Botânica no Brasil e deixa claro a importância de entendermos como os sujeitos envolvidos no processo de ensino/aprendizagem compreendem e enxergam o ensino no país (PINTO; SILVA, 2009, ARRAIS et al., 2014, SALATINO; BUCKERIDGE ,2016). Sendo assim, quando pensamos sobre o conceito de "cegueira botânica", cunhado por Wandersee \& Schussler (2002), analisamos as causas e consequências da não percepção das 
plantas pelas pessoas em seu ambiente natural. A não valorização no ensino com relação às plantas, dificulta e atrapalha sobremaneira o ensino de botânica nas escolas.

Ressaltamos que nossa proposta de trabalho com o conceito de "cegueira botânica", não analisa literalmente o termo cegueira, visto a partir da deficiência visual, pois, os deficientes visuais podem, apesar de suas limitações identificar e perceber a existência das plantas no ambiente. Portanto, nosso foco é entendermos como está ocorrendo o ensino de botânica nas escolas da rede estadual de ensino médio e propor a utilização de metodologias diferenciadas e que estimulem o protagonismo dos estudantes no processo de ensino/aprendizagem, permitindo assim, o fornecimento de ferramentas didáticas alternativas para a superação das dificuldades encontradas pelos professores no ensino de biologia nas escolas.

Para que não haja dúvida entre a cegueira que indique incapacidade ou habilidade e aquela literal para a deficiência em enxergar, podemos sugerir o termo insciência botânica, que significaria o que estamos designando, a não capacidade de perceber as plantas quando estas estão entremeada aos animais ou até mesmo quando se analisa o meio ambiente como um todo. Dessa forma apropriamos do termo insciência seguindo o conceito apontado em Insciência (2020).

Sendo assim, o objetivo do presente estudo foi avaliar as possibilidades didáticas das aulas de campo e das coleções botânicas com enfoque em herbário juntamente com uso das Tecnologias Digitais da Informação e Comunicação - TDICs para o enriquecimento do ensino de botânica de uma escola estadual de ensino médio do município de Tangará da Serra, Mato Grosso.

\section{REFERENCIAL TEÓRICO}

O ensino de botânica apresenta sérias dificuldades no que se refere à assimilação de conceitos e participação ativa dos alunos no processo de ensino/aprendizagem. Muitos desses problemas estão atrelados a prática docente tradicional, demonstrando a necessidade de ressignificação do ensino de botânica e de biologia na educação básica (MOREIRA et al., 2019).

Vygotsky (1896-1934) por exemplo, aponta que o desenvolvimento do indivíduo e a aquisição de conhecimentos é resultante da interação do mesmo com o meio, através de um processo sócio histórico mediado pela cultura e construído coletivamente. Sendo assim, é fundamental que o aluno perceba o conhecimento ensinado como algo significativo para sua vida. 
Dessa maneira, a formação do(a) Professor(a) por mais completa que seja, nem sempre consegue prepará-lo(a) para o enfrentamento das dificuldades encontradas na realidade escolar, como, por exemplo, falta de infraestrutura, de recursos e materiais didáticos para a efetivação de seu trabalho. E, devido a esses fatores, torna-se necessário o professor atualizar-se sempre e buscar formas alternativas de diversificar sua prática pedagógica, para assim, despertar a curiosidade dos alunos para o conhecimento, dentre eles o científico, desde as séries iniciais (VIECHENESKI; CARLETTO, 2013). Nesse sentido, o processo de diversificação da prática pedagógica pode ampliar o campo de ação do fazer docente, permitindo alcançar as distintas necessidades e interesses dos alunos e atraí-los para o processo educativo de forma mais fácil (VIVEIRO; DINIZ, 2009).

No processo de diversificação da prática pedagógica, os professores têm papel fundamental, pois compete aos mesmos vencer os receios que venham a ter sobre a realização desse tipo de ação, como por exemplo, o de perder o controle da turma e gerar situações de indisciplina em sala de aula. Ao docente, compete o entendimento de que para promover a dinamização de suas aulas, como em aulas práticas, não é necessariamente imprescindível a existência de um laboratório, pois os ambientes não formais de ensino como jardins, parques, feiras são ótimos recursos alternativos (LIMA et al., 2013).

Nesse âmbito, observa-se que uma pequena parcela das escolas públicas brasileiras possuem laboratório de ciências. Isto aponta para a necessidade de os professores planejarem aulas diferenciadas que façam os alunos se envolverem e se interessarem pelos temas estudados, promovendo o desenvolvimento do pensamento investigativo e curiosidade pela ciência. (SOARES; BAIOTTO, 2015). Ainda, apesar de as aulas teóricas serem importantes fontes de aprendizado, o uso único dessa forma de ensino, torna-se desanimadora aos alunos, sobretudo no estudo das plantas, que tradicionalmente passam despercebidas pela maioria das pessoas, apenas como partes integrantes da paisagem (WANDERSEE; SCHUSSLER, 2001). Além disso, aulas práticas aproxima os alunos para o objeto de estudo e proporciona maior encantamento pelo conhecimento cientifico (PINTO; SILVA, 2009), além, é claro, de estimular o(a) docente a encarar com propriedade o labor da sala de aula.

Em se tratando do estudo das plantas, nosso país dispõe de uma das mais ricas floras mundiais, distribuída nos diversos complexos vegetacionais, como o cerrado, por exemplo. A diversidade de espécies, aliada as variantes morfológicas naturais dificultam a correta identificação das plantas e, nesse sentido, a taxonomia auxilia na identificação e classificação desse grupo (FONSECA; VIEIRA, 2001, PEIXOTO; MORIM, 2003). Com isso, a partir da 
identificação e classificação desses exemplares, torna-se possível realizar os inventários botânicos nas diversas áreas amostradas. Desses inventários, surgem as chamadas coleções botânicas denominadas de herbários, caracterizadas por abrigarem plantas inteiras ou partes de plantas secas como repositórios científicos permanentes (PEIXOTO et al., 2007), e também didáticas que podem ser usadas nas escolas como recursos de aprendizagem. Dessa forma, o uso de coleções botânicas didáticas pode vir ao encontro das recomendações de inserção da investigação cientifica no ensino de biologia, conforme Krasilchik (2016). Assim, a montagem e utilização de um herbário no ambiente escolar se apresenta como ferramenta didática válida no ensino de botânica (NUNES et al., 2015) e pode ser o principal material instrumental do qual o(a) docente pode se apropriar unindo o trabalho dos(das) discentes e fomentando a participação dos(das) mesmos(as) dentro e fora da sala de aula.

\section{Metodologia}

A pesquisa foi realizada em uma escola da rede estadual de ensino, Escola Estadual 13 de Maio, no município de Tangará da Serra-MT. O município, segundo dados do Instituto Brasileiro de Geografia e Estatística (IBGE), possuía no ano de 2018, uma população com 101.764 pessoas (IBGE, 2018).

Para a coleta de dados, foram realizadas três aulas de campo com subsequentes atividades de laboratório para classificação e montagem da coleção botânica didática com enfoque em herbário. Para a seleção dos alunos participantes, foi montado e apresentado aos mesmos o "Projeto Botânica no Cerrado", que foi previamente aprovado pelo Conselho Deliberativo da Comunidade Escolar - CDCE da unidade de ensino. Dessa forma, a participação dos alunos nas atividades de campo e laboratório foi voluntária, visto que, ocorreram fora do horário normal de aulas. Os alunos que aceitaram participar do projeto, 25 no total, receberam o Termo de Assentimento - TA e Termo de Consentimento Livre e Esclarecido - TCLE, para apreciação e aprovação dos pais e/ou responsáveis. Todas as etapas de execução da pesquisa seguiram as recomendações e pré-requisitos do Comitê de Ética em Pesquisa - CEP da Universidade do Estado de Mato Grosso - UNEMAT e foram aprovados pelo parecer de número 3.019.414.

As aulas de campo foram realizadas durante o ano letivo de 2018, planejadas com foco no estudo dos vegetais típicos do bioma cerrado. Antes da realização das aulas práticas e de campo, foram apresentadas aos alunos as técnicas e materiais de coleta e herborização (Figura 1), bem como informações sobre a vegetação típica do bioma cerrado. 
Figura 1 - Apresentação do Projeto "Botânica no cerrado" aos alunos da EE 13 de Maio, Tangará da Serra, MT

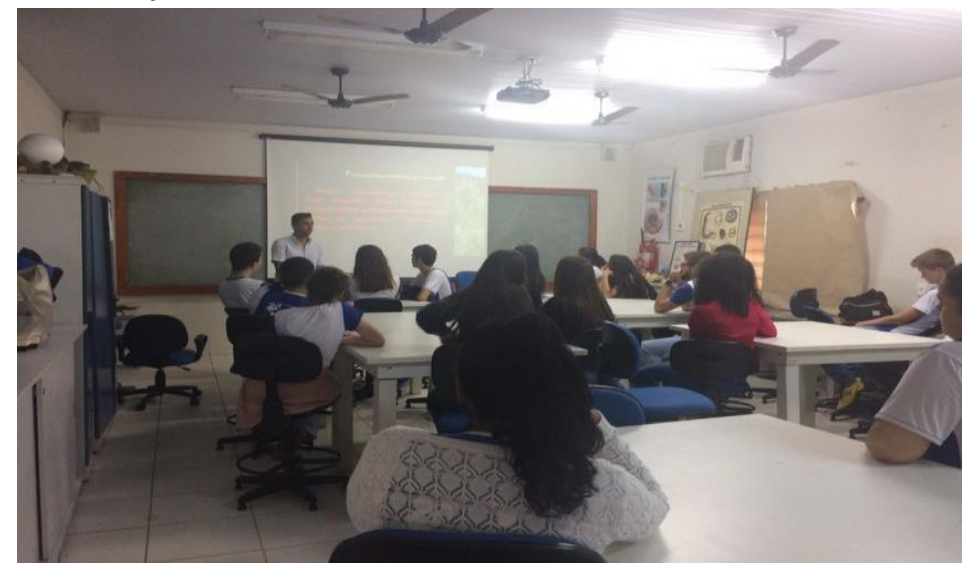

Fonte: Autores, 2018.

Utilizando-se das redes sociais como apoio, foi montado um grupo de WhatsApp para repassar informações sobre o projeto. No grupo; repassamos material teórico e manuais em formato digital para auxiliar na identificação de material botânico durante as aulas de campo e para permitir a troca de ideias e conhecimentos durante o período de realização do projeto. $\mathrm{O}$ material coletado foi depositado no mini herbário construído no laboratório de biologia da EE 13 de Maio de Tangará da Serra-MT. O processo de identificação dos exemplares coletados foi realizado na UNEMAT de Tangará da Serra, por profissionais, especialistas em plantas, convidados.

Os locais escolhidos para a realização das aulas de campo foram selecionados levandose em conta a facilidade de acesso de alunos e professores, logística e presença de vegetação típica do bioma estudado. Sendo assim; optou-se por realizar as atividades de campo em locais conhecidos do município, o distrito de Joaquim do Boche, balneário Salto das Nuvens e pesqueiro Piracema. Essas localidades apresentam uma vegetação de transição entre cerrado e floresta amazônica, as distinções e fitofisionomias foram abordadas e utilizadas como mais um dos temas de ensino utilizadas. As alterações ambientais (antrópicas) também foram comentadas durante as coletas.

As aulas práticas sobre técnicas de herborização e montagem das exsicatas foram realizadas no laboratório de biologia da EE 13 de Maio de Tangará da Serra, MT. Assim como as aulas de campo, a atividade foi realizada fora do horário de aula normal dos alunos, sendo assim, tivemos a participação voluntária dos mesmos.

Após o processo de identificação dos exemplares da flora coletados, os alunos receberam uma formação para a produção de $Q R$ Codes, para fornecer informações complementares as exsicatas produzidas. Foi utilizado o site: Crie QR Codes personalizado, 
Criar Códigos QR individual <http://www.informacaovirtual.com/tecnologia/aprenda-a-usaro-qr-code> (Figura 2). Para a criação dos $Q R$ Codes, os alunos deviam, com base na identificação cientifica das exsicatas, pesquisar na internet informações adicionais sobre a espécie, como a distribuição geográfica, os usos e importância ecológica e econômica.

Figura 2 - Layout da página da internet utilizada para a criação dos QR Codes pelos alunos participantes da pesquisa

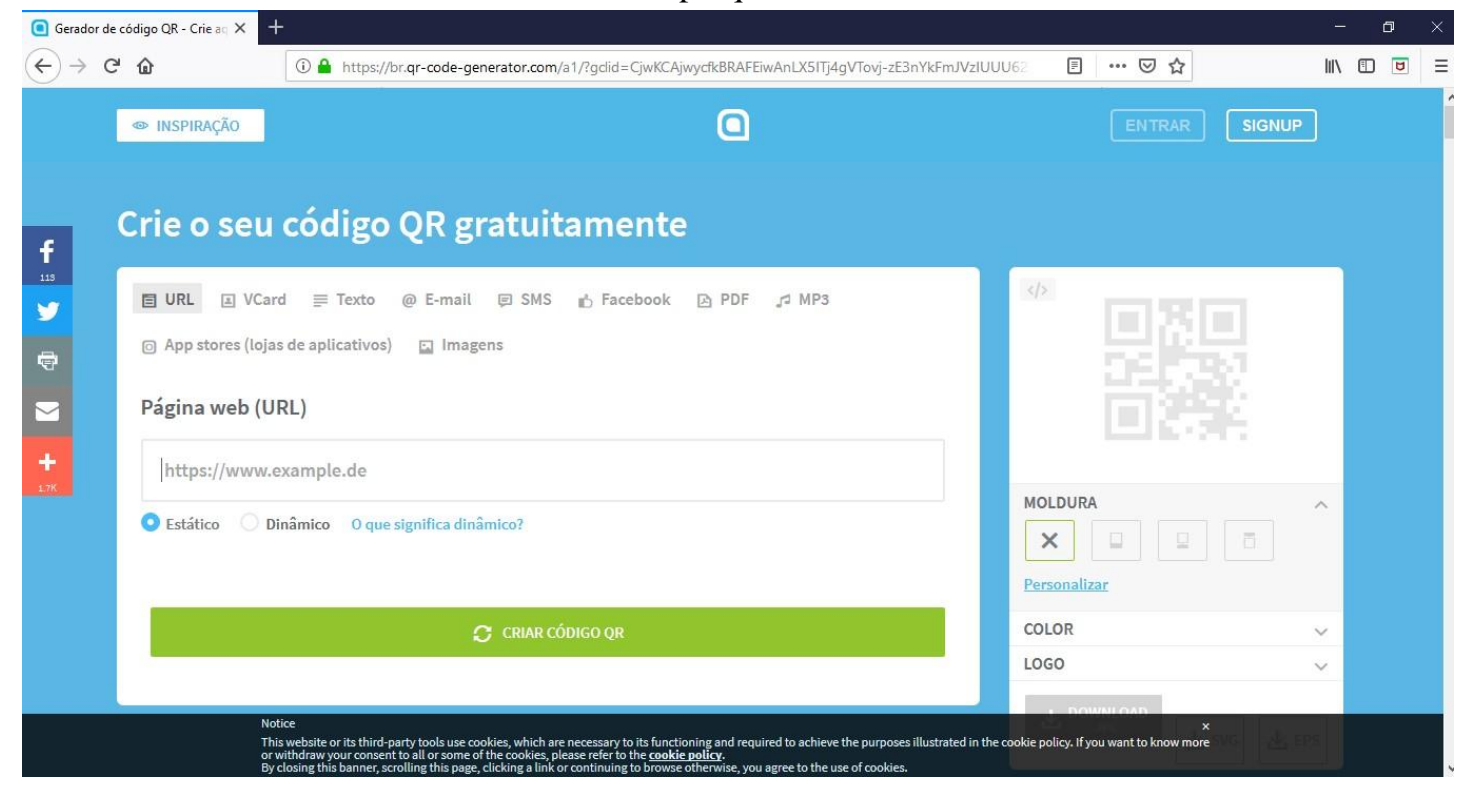

Fonte: https://br.qr-code-generator.com, 2018.

Após a coleta de informações com alunos e professores sobre como se procedia o ensino de Botânica na unidade de ensino estudada, elaboramos sequências didáticas para o ensino de diferentes conteúdos de botânica. As mesmas foram planejadas a partir das informações recolhidas que vinham de encontro a um processo de ensino de botânica regionalizado, interativo, participativo e que permitisse a curiosidade e participação dos alunos no processo de ensino/aprendizagem.

Aulas práticas e de campo permitem o fortalecimento do conhecimento aprendido dentro da sala de aula, aproxima o(a) discente da disciplina e possibilitam a construção de sequências didáticas que podem ser deixadas como sugestões de ensino-aprendizagem a outros docentes em outras oportunidades.

Segundo Santos et al. (2016) as sequências didáticas são objetos ou artefatos sociotécnicos que favorecem o estabelecimento de uma rede onde estão entrelaçadas entidades não humanas e humanas. Segundo os autores as entidades não humanas englobam uma variada gama de entidades como fenômenos naturais, conceitos da atualidade ou objetos físicos como elementos da natureza e produtos do trabalho humano. Essa visão rompe com a tradicional 
visão cognitivista e mentalista da aprendizagem, abrindo caminho para diferentes possibilidades educativas e permitindo a construção de sequências didáticas que estabeleçam maior significado aos alunos e professores.

As sequências didáticas produzidas neste trabalho foram aplicadas aos alunos da escola como forma de teste e em seguida aquelas que demonstraram melhores resultados quanto a participação dos estudantes, experimentação e aplicação da pesquisa científica na escola, valorização da vegetação típica da região e dinamismo no ensino da botânica, foram compiladas e compuseram um guia com sequências didáticas que servirá como recurso didático aos professores de biologia do ensino médio.

\section{Resultados}

\subsection{Aulas de CAMPo NO ENSINO DE BOTÂNICA}

Por meio das atividades de campo e laboratório desenvolvidas nesse estudo, foi possível observar maior envolvimento dos alunos pelos conceitos botânicos ensinados, o que demonstra a importância do processo de dinamização e diversificação da prática pedagógica como forma de gerar maior atenção para as plantas.

Sobre isso, Ursi et al. (2018) dizem que a aprendizagem se torna mais significativa na junção teoria-prática e por meio da contextualização dos conteúdos, pois se observa maior compreensão e entendimento dos assuntos relacionados à botânica. Com isso, as atividades de campo e laboratório realizadas durante o ano letivo de 2018 no projeto "Botânica no Cerrado", atingiram o objetivo de dinamizar o ensino de biologia, visto que, apesar de termos trabalhado com um grupo de alunos dos diferentes níveis escolares do Ensino Médio, conseguimos observar o envolvimento desses alunos nas etapas e atividades realizadas, como podemos observar nas imagens abaixo (Figura 3). 
Figura 3 - Alunos realizando as atividades solicitadas durante as aulas de campo, nos três locais selecionados para o estudo

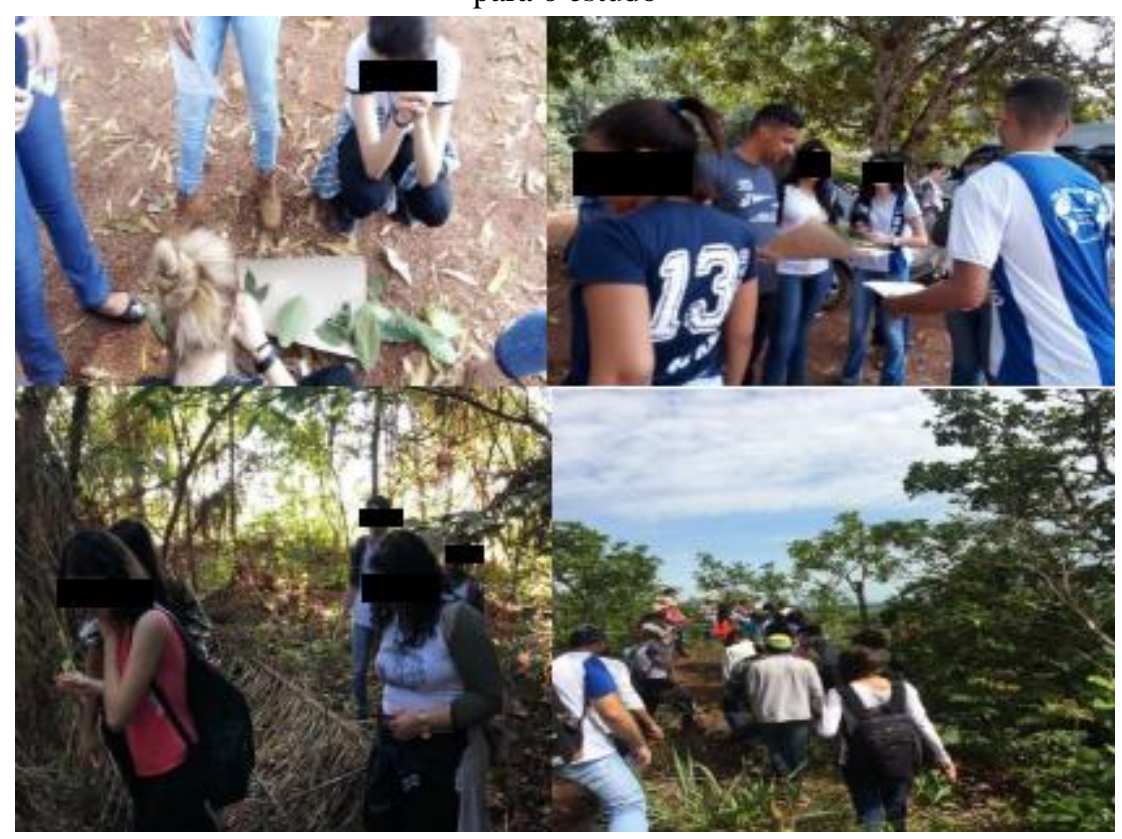

Fonte: Autores, 2018

Quanto ao uso da vegetação local como recurso didático, percebemos a importância da valorização e trabalho com a diversidade local, observado pela fala de dois alunos:

\section{A1- "Essa árvore tem no sítio do meu avô" \\ A2 - "Essa árvore aqui é a paineira. Não é? Eu conheço como paineira"}

Fica claro pela fala dos alunos, que o reconhecimento das espécies durante as aulas de campo demonstra a importância da valorização do conhecimento prévio do aluno e consequente utilização do mesmo para incentivar a curiosidade pelas plantas. Sendo assim, tais relatos reforçam a importância de estreitarmos os laços entre os conhecimentos prévios dos alunos com os novos saberes ensinados na escola.

Tal valorização está incluída inclusive nos livros didáticos utilizados nas escolas, em que se observam a inserção de propostas de atividades que levam em consideração as concepções intuitivas dos discentes (MACHADO, 2015).

Quando pensamos na ampliação dos espaços educativos visando tornar o ensino mais atrativo, é inevitável pensarmos em atividades ao ar livre e fora do ambiente escolar. Essa interação como o ambiente externo atua como um agente estimulador da aprendizagem e desenvolvimento cognitivo do aluno. Segundo alguns dos principais teóricos cognitivistas, como Vygotsky, Piaget e Wallon, é necessário compreender a ação do sujeito no processo de construção do conhecimento e mesmo que observemos pontos distintos em suas teorias, todos relatam e procuram entender como a aprendizagem ocorre (CARMO; BOER, 2012). Nessa 
perspectiva, a troca de experiências entre alunos e professores na atividade de campo se mostrou como um momento de troca de experiências e construção de novos saberes acerca do meio visitado.

\subsection{AS COLEÇÕES BOTÂNICAS COM ENFOQUE EM HERBÁRIO}

Por meio das atividades desenvolvidas, envolvendo a construção da coleção botânica didática, observou-se incremento da motivação e envolvimento dos estudantes pelo estudo das plantas. O projeto foi desenvolvido fora da sala de aula e em momentos fora do horário normal de aulas, mas demonstrou ser uma possibilidade didática muito interessante para ser desenvolvida de forma paralela as atividades de ensino programadas.

A motivação desempenhada pelos alunos no momento da prática de campo confirmou a fixação dos conceitos de sala de aula e demonstrou a apreensão dos conteúdos de sala. Assim, estes dados podem ser corroborados por Fagundes e Gonzalez (2006) que concluíram que as atividades oferecidas em uma proposta de herbário escolar podem contribuir para o processo de aprendizado botânico no Ensino Médio.

Neste estudo, a escolha de trabalho e valorização da flora do cerrado, fomentou a curiosidade e permitiu aos alunos da EE 13 de Maio de Tangará da Serra, entrarem em contato direto com o ambiente natural, utilizando todos os sentidos no processo de interação como o meio ambiente estudado. Ainda, as atividades de campo ampliam o trabalho do docente que por muitas vezes se encontravam sobrecarregados em suas cargas horárias da escola ou até mesmo com outras escolas do município. No entanto, o retorno obtido nos trabalhos de campo satisfizam o objetivo do docente que é "perceber" a aprendizagem em sua forma integra.

Além da interação e contato com a vegetação típica do bioma, os alunos puderam vivenciar os métodos de campo utilizados por estudiosos da área de botânica e ecologia, podendo dessa forma, entrar em contato com o processo de investigação científica e aprender na prática os conceitos que seriam repassados apenas na teoria (Figura 4). 
Figura 4 - Atividades de campo e laboratório desenvolvidas com os estudantes da EE 13 de Maio durante o ano letivo de 2018

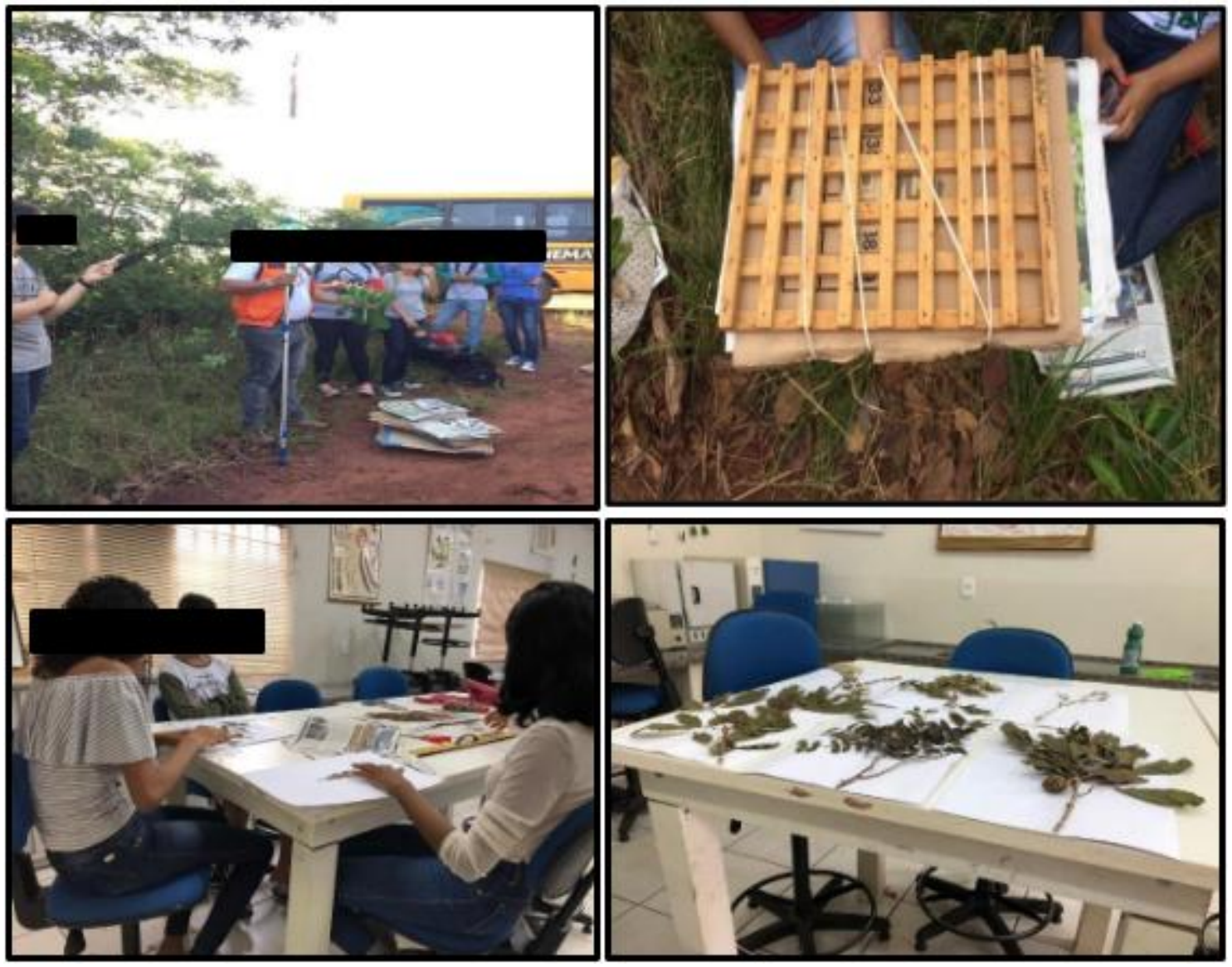

Fonte: Autores, 2018.

Sendo assim, como observamos na figura 4 os alunos participantes do projeto "Botânica no cerrado", foram protagonistas durante todo o processo de realização do estudo, aprendendo e aplicando o conhecimento na prática, como o necessário na coleta das plantas e montagem das exsicatas.

\subsection{USO DAS TDICS NO ENSINO DE BOTÂNICA}

Além da etiqueta padrão utilizada para identificação das exsicatas, os alunos elaboraram os $Q R$ Codes e posteriormente baixaram aplicativos de leitura dos códigos em seus smartphones, os alunos puderam atuar como disseminadores da proposta para os demais colegas que não participaram do projeto "Botânica no Cerrado", fornecendo assim, informações de cada espécie do acervo montado por meio do projeto.

Segundo Ribeiro (200?), o QR Code (Quick Response Code) se apresenta como uma espécie de código de barras bidimensional, tendo sido criado em 1994 pela empresa japonesa Denso Wave. Esse código pode ser obtido mesmo em baixas resoluções, como nas imagens feitas por câmeras VGA, como as encontradas nos aparelhos de celular mais básicos, e dessa 
forma, o código pode ser interpretado rapidamente e sem erros. A opção por essa ferramenta se deve a necessidade de adequação aos recursos tecnológicos disponíveis, que conferem aos estudos uma abordagem atual e conectada às expectativas do público discente do século XXI, bem como motivam os sujeitos colaboradores desta pesquisa, alunos do ensino médio, de participarem efetivamente de todo o percurso da pesquisa.

Para Machado (2016), o fazer docente passa a ter uma nova roupagem, quando o uso dos ambientes colaborativos mediados pelas TDICs passam a integrar o ensino do século XXI e devem permitir a construção do conhecimento, mediado pelas tecnologias digitais, em que os alunos da geração internet façam uso das comunidades virtuais para se relacionar e compartilhar informações. Dessa forma, o grupo de WhatsApp criado para o compartilhamento de informações e ações desenvolvidas durante a realização do projeto "Botânica no cerrado", demonstrou cumprir seu papel no processo de construção coletiva do conhecimento. A ação docente, antes baseada na autoridade, ganha uma nova perspectiva ao utilizar-se de ambientes colaborativos mediados pelas TDICs, inclusive tornando ambos professores e alunos protagonistas.

Figura 5 - Exemplo de exsicata produzida pelos alunos com utilização do Qr code

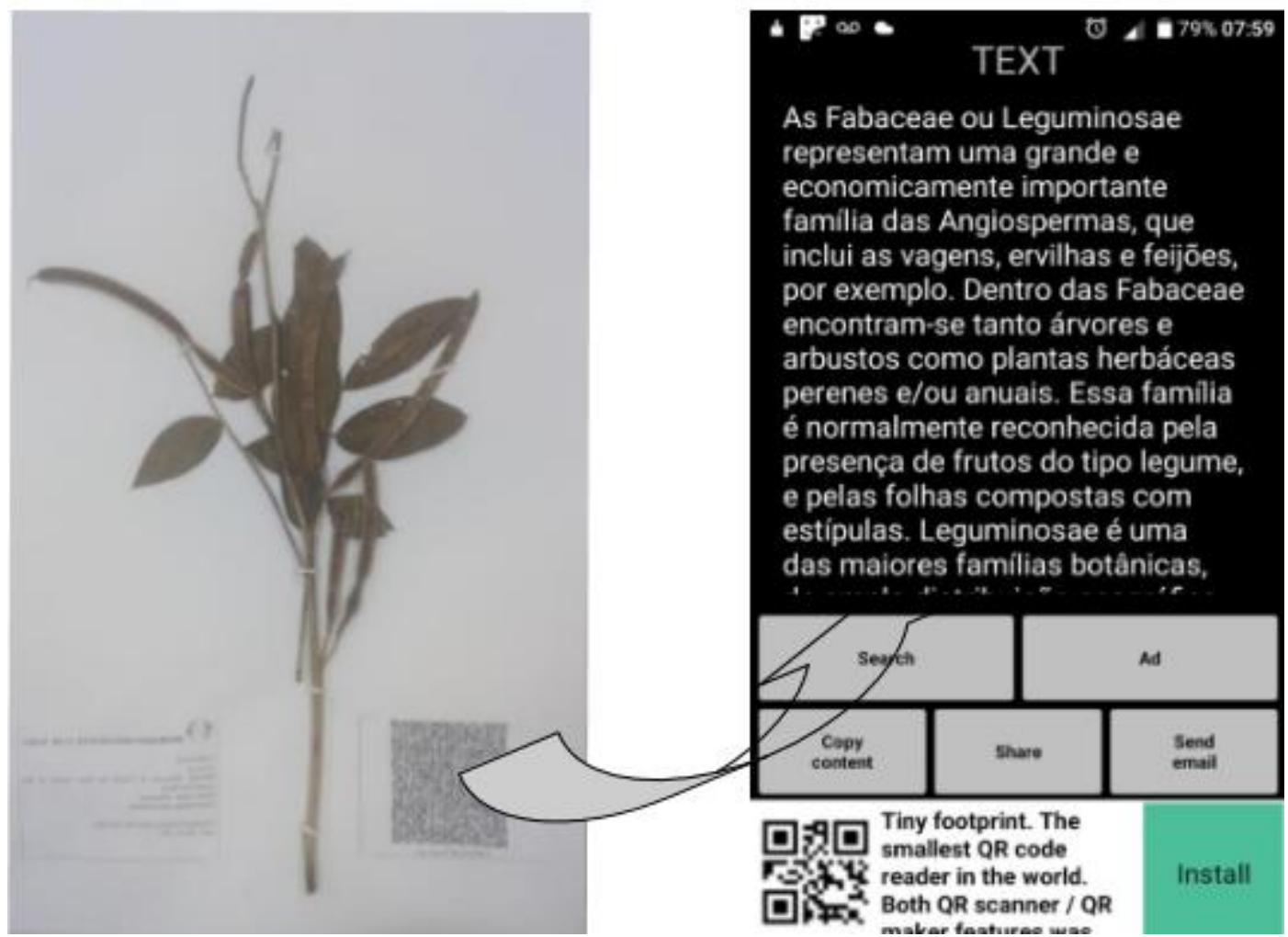

Fonte: Autores, 2019. 
Conforme a Figura 5 a utilização do Qr code como fonte de informação adicional as exsicatas contribuiu para a inserção das tecnologias digitais no ensino de botânica na escola EE13 de Maio de Tangará da Serra, MT. Destacamos que o material produzido tinha como foco a produção de material didático para auxílio no fazer docente, sendo assim, um motivador para o trabalho com as plantas e dinamização do processo de ensino/aprendizagem.

\subsection{SEQUÊNCIAS DIDÁTICAS PARA O ENSINO DE BOTÂNICA}

Segundo Santos et al. (2016), as sequências didáticas são objetos ou artefatos sociotécnicos que favorecem o estabelecimento de uma rede onde estão entidades não humanas e humanas. Segundo os autores as entidades não humanas englobam uma variada gama de entidades como fenômenos naturais, conceitos da atualidade ou objetos físicos como elementos da natureza e produtos do trabalho humano.

Essa visão rompe com a tradicional visão cognitivista e da aprendizagem, abrindo caminho para diferentes possibilidades educativas e permitindo a construção de sequências didáticas que estabeleçam maior significado aos alunos e professores. Dessa maneira, elaboramos ao final do processo investigativo um guia de sequências didáticas para o ensino de botânica (Figura 6) para auxiliar os professores de ciências e biologia no planejamento e execução de aulas teórico-práticas, com enfoque no estudo das plantas típicas do bioma cerrado.

Figura 6 - Guia com sequências didáticas produzidas ao final do processo investigativo como recurso didático aos docentes

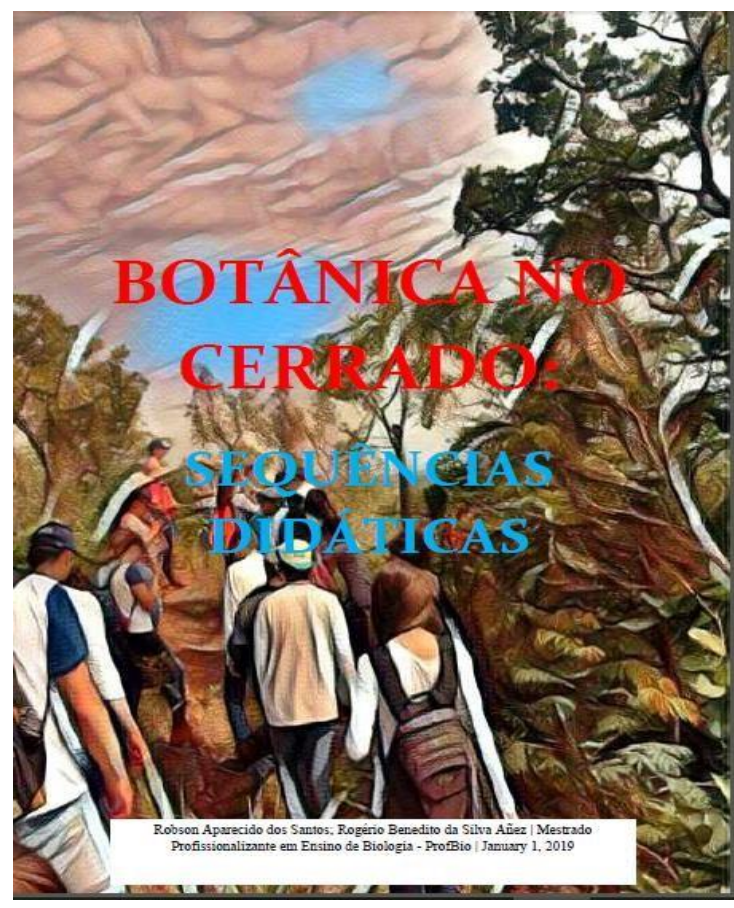

Fonte: Autores, 2018. 
As propostas de aulas apresentadas no texto são de fácil adequação ao ambiente vivenciado pelos docentes e discentes e demandam pouco recursos financeiros para a sua implementação nas escolas da rede pública de ensino.

O guia elaborado por meio do projeto "Botânica no cerrado", apresenta propostas de trabalho com temas diversos ligados à botânica, como a importância das plantas para as pessoas, plantas vasculares e avasculares e anatomia vegetal. O texto se propõe a mostrar e sugerir possibilidades de diminuirmos a desvalorização das plantas no ensino de biologia na educação básica e desenvolver o pensamento científico investigativo nos alunos.

\section{CONSIDERAÇÕES FINAIS}

Percebemos por fim, que as propostas de atividade desenvolvidas com o grupo de alunos do ensino médio durante a realização do projeto "Botânica no cerrado", esteve de acordo com as expectativas de aprendizagem do público alvo quanto a possibilidade de adequação dos conteúdos as características ambientais locais e uso das TDICs para melhorar o processo de aprendizagem dos alunos. A coleção didática botânica com enfoque em herbário produzida pelos alunos, apesar de estar em início na EE 13 de Maio, fomentará novos trabalhos e atividades de campo com demais turmas de alunos e professores regentes na unidade de ensino da rede pública do município de Tangará da Serra, MT.

Outro ponto relevante desse estudo se relaciona a interação entre alunos de turmas diferentes que favorece sobremaneira a troca de experiências e saberes entre a comunidade escolar. O grupo de WhatsApp possibilitou o uso didático de uma ferramenta tecnológica de amplo acesso e uso pelos alunos, ressignificando o uso das tecnologias por parte dos alunos. Dessa forma, acreditamos que as novas tecnologias, se utilizadas da forma correta, podem contribuir para o enriquecimento do ensino da botânica e das demais áreas do conhecimento.

\section{REFERÊNCIAS}

ARRAIS, Maria das Graças Medina; SOUZA, Gardene Maria de; MASRUA, Mariana Lenara de Andrade. O ensino de botânica: investigando dificuldades na prática docente. Revista da SBEnBio - n ${ }^{\circ}$, out. 2014.

CARMO, Enedina Silva do; BOER, Noemi. Aprendizagem e Desenvolvimento na perspectiva interacionista de Piaget, Vygotsky e Wallon. XVI Jornada Nacional de Educação. Centro Universitário Franciscano (UNIFRA). Santa Maria, RS: 2012.

FITA, Dídac Santos; NETO, Eraldo Medeiros Costa. As interações entre os seres humanos e os animais: a contribuição da etnozoologia. Revista Biotemas, 20 (4), dezembro de 2007. 
FONSECA, Rúbia Santos; VIEIRA, Milene Faria. Coleções botânicas com enfoque em herbário [Recurso eletrônico]. Viçosa, MG: Ed. UFV, 1984-2001.

FAGUNDES, José Anevan; GONZALEZ, Carlos Eduardo Fortes. Herbário escolar: suas contribuições ao estudo da Botânica no Ensino Médio. Paraná, 2006. Dissertação (Mestrado em tecnologia) - Universidade Tecnológica Federal do Paraná.

IBGE - Instituto Brasileiro de Geografia e Estatística. Tangará da Serra - IBGE Cidades. Disponível em: https://cidades.ibge.gov.br/brasil/mt/tangara-da-serra/panorama. Acesso em: 20/08/2018.

INSCIÊNCIA. In: DICIO, Dicionário Online de Português. Porto: 7Graus, 2020. Disponível em: https://www.dicio.com.br/insciencia/. Acesso em: 10/08/2020

KRASILCHIK, Myriam. Prática de Ensino de Biologia, 4 ed. São Paulo: Ed. da Universidade de São Paulo, 2016.

LIMA, Aguinel Messias de; OLIVEIRA, Haydée Torres de. A (re) construção dos conceitos de natureza, meio ambiente e educação ambiental por professores de duas escolas públicas. Ciênc. educ. (Bauru) vol.17 no.2 Bauru 2011.

LIMA, Jane Helen Gomes de.; SIQUEIRA, Ana Paula Pruner de; COSTA, Samuel. A utilização de aulas práticas no ensino de ciências: um desafio para os professores. $\mathbf{2}^{\mathbf{0}}$ Simpósio de Integração Científica e Tecnológica do Sul Catarinense - SICT-Sul, 2013.

MACHADO, Júlio César Epifânio. Os conhecimentos prévios dos Alunos no ensino de geografia: apontamentos para a organização das aulas Revista Brasileira de Educação em Geografia, Campinas, v. 5, n. 10, p. 114-125, jul. /Dez, 2015.

MACHADO, Silvia Cota. Análise sobre o uso das tecnologias digitais da informação e comunicação (TDICs) no processo educacional da geração Internet. Novas Tecnologias na Educação, v. 14 n 2 2, dezembro, 2016.

MELO, Edilaine Andrade; ABREU, F. F.; ANDRADE, A. B.; ARAÚJO, M. I. O. A aprendizagem de botânica no ensino fundamental: dificuldades e desafios. Scientia Plena 8, Vol. 8, Num. 10, 2012.

MOREIRA, Luiz Henrique Liberato; FEITOSA, Antônia Arisdélia Fonseca Matias Aguiar; QUEIROZ, Rubens teixeira de. Estratégias pedagógicas para o ensino de botânica na educação básica. Experiências em Ensino de Ciências V.14, No.2, 2019. Disponível em: https://if.ufmt.br/eenci/artigos/Artigo_ID618/v14_n2_a2019.pdf. Acesso em: 20/11/2019.

NUNES, Maria de Jesus Miranda; OLIVEIRA, Thaynara Fontenele de; SOUZA, Ruanna Thaimires Brandão; LEMOS, Jesus Rodrigues. Herbário didático como ferramenta diferenciada para a aprendizagem em uma escola de Ensino Médio em Parnaíba, Piauí. Momento, ISSN 0102-2717, v. 24 n. 2, p. 41-55, jul. /Dez 2015.

PEIXOTO, Ariane Luna; MORIM, Marli Pires. Coleções botânicas: documentação da biodiversidade brasileira. Ciência e Cultura. vol.55 no.3 São Paulo July/Sept. 2003. 
PEIXOTO, Ariane Luna; BARBOSA, Maria Regina de Vasconcellos; CANHOS, Dora Ann Lange; MAIA, Leonor Costa. 2007. Coleções botânicas: objetos e dados para a ciência. Cultura Material e Patrimônio de C\&T. Pp. 315-326.

PINTO, Andressa vial. SILVA, Tatiana Araújo da. Importância das aulas práticas na disciplina de botânica. Trabalho de Conclusão de Curso (licenciatura). Faculdade Assis GURGACZ -FAG, Cascavel- FAG, 2009.

RIBEIRO, Rodrigo Neto. Aprenda a usar o QR Code. Disponível em: http://www.informacaovirtual.com/tecnologia/aprenda-a-usar-o-qr-code. Acesso em: $30 \mathrm{Ag}$. 2017.

SALATINO, Antônio; BUCKERIDGE, Marcos. "Mas de que te serve saber botânica?". Estudos Avançados 30(87), 2016.

SANTOS, Victor Marcondes de Freitas, COUTINHO, Francisco Ângelo; SILVA, Fábio Augusto Rodrigues e. A proposta Teoria Ator-Rede (ANT) para a construção de sequências didáticas. Sequências didáticas: propostas, discussões e reflexões teóricometodológicas /Francisco Ângelo Coutinho, Fábio Augusto Rodrigues e Silva (org.). -- Belo Horizonte: FAE/UFMG, 2016. Disponível em:

https://www.repositorio.ufop.br/bitstream/123456789/8549/1/CAPITULO_EstatutoEmbri\%C 3\%A3oPesquisa.pdf. Acesso em 12/03/2019.

SOARES, Raquel Madeira; BAIOTTO, Cléia Rosani. Aulas práticas de biologia: suas aplicações e o contraponto desta prática. REVISTA DI@LOGUS ISSN 2316-4034 - Volume $4 n^{\circ} 2,2015$.

URSI, Suzana; BARBOSA, Pércia Paiva.; SANO, Paulo Takeo.; BERCHEZ, Flávio Augusto de Souza. Ensino de Botânica: conhecimento e encantamento na educação científica, Estudos Avançados 32 (94), 2018. Disponível em:

https://www.scielo.br/scielo.php?script=sci_arttext\&pid=S0103-40142018000300007. Acesso em: 15/03/2019.

VIECHENESKI, Juliana Pinto.; CARLETTO, Márcia. Por que e para quê ensinar ciências para crianças. R. Bras. de Ensino de C\&T, vol 6, núm. 2, mai-ago.2013.

VIVEIRO, Alessandra Aparecida.; DINIZ, Renato Eugênio Silva. Atividades de campo no ensino das ciências e na educação ambiental: refletindo sobre as potencialidades desta estratégia na prática escolar. Ciência em Tela, vol. 2, n. 1, 2009.

WANDERSEE, James H..; SCHUSSLER, Elisabeth. Toward a theory of plant blindness. Plant Science Bulletin, Columbus, v. 47, n. 1, p. 2-9, 2001.

Recebido em: 12 de março de 2019. Aprovado em: 14 de maio de 2019. 